\title{
Situação da tuberculose em ovinos consorciados com bovinos leiteiros na região sudoeste maranhense
}

\author{
State of tuberculosis in sheep bred with \\ dairy cattle in the southwest region of Maranhão
}

\author{
Rosiane de Jesus Barros', Roberto Soares de Castro², Nancyleni Pinto Chaves', \\ Adriano Mendes Moura', Michelle Lemos Vargens' ${ }^{1}$, Daniel Praseres Chaves ${ }^{3 *}$
}

RESUMO: Objetivando conhecer a situação da tuberculose ovina no Maranhão, avaliaram-se 343 ovinos da região sudoeste do estado, 247 fêmeas e 96 machos, com idade acima de 6 meses, por meio do teste cervical comparativo (TCC), com inoculação de tuberculinas na região cervical direita. Cranialmente, injetou-se derivado proteico purificado (PPD) aviário; e caudalmente, PPD bovino, em doses individuais de $0,1 \mathrm{~mL}$. Todos os animais apresentaram resultado negativo para tuberculose, entretanto, 65 ovinos apresentaram reação à tuberculina bovina superior à aviária. Para investigar a possibilidade de baixa sensibilização ou anergia em animais com tuberculose avançada, foi necropsiado um ovino caquético, idade acima de quatro anos, com resultado negativo ao TCC, porém, com reação à tuberculina aviária e linfonodos aumentados com consistência endurecida. Os resultados indicaram infecções por $C$. pseudotuberculosis, Actinomyces pyogenes, Staphylococcus aureus e Mycobacterium sp. A cultura e o isolamento resultaram em Pseudomonas aeruginosas e Bacillus sp. Não foram visualizadas estruturas bacterianas compatíveis com bacilo álcool ácido resistente (BAAR). Os resultados confirmam ausência de animais reagentes ao $M$. bovis, pressupondo inexistência da tuberculose em ovinos na região estudada.

PALAVRAS-CHAVE: bacterioscopia; diagnóstico; histopatológico; teste cervical comparativo; tuberculina.

\begin{abstract}
In order to know the situation of ovine tuberculosis in Maranhão, Brazil, we evaluated 343 sheep in the southwest region of the state, of both sexes (247 females and 96 males), aged over six months, through the comparative cervical test (TCC), with tuberculin inoculation in the right cervical region. Cranially, avian purified protein derivate (PPD) was injected; and caudally, beef PPD was injected, in individual doses of $0.1 \mathrm{~mL}$. All animals were negative for tuberculosis; however, 65 sheep had higher reactions to bovine tuberculin than to the avian one. To investigate the possibility of low awareness or anergy in animals with advanced tuberculosis, one cachectic sheep was necropsied, aged four years, with negative results for TCC, but with reaction to avian tuberculin and enlarged hardened lymph nodes. The results indicated C. pseudotuberculosis, Actinomyces pyogenes, Staphylococcus aureus and Mycobacterium sp infections. Culture and isolation resulted in Pseudomonas aeruginosa and Bacillus sp. No bacterial structures compatible with acid-fast bacteria were found. The results confirmed the absence of animals reactive to $M$. bovis, assuming no tuberculosis in sheep in the study area.
\end{abstract}

KEYWORDS: bacterioscopy; diagnosis; histopatologic; cervival comparative test; tuberculin.

\footnotetext{
'Agência Estadual de Defesa Agropecuária do Maranhão (AGED/MA) - São Luís (MA), Brasil.

${ }^{2}$ Departamento de Medicina Veterinária, Universidade Federal Rural de Pernambuco (UFRPE) - Recife (PE), Brasil.

${ }^{3}$ Departamento de Patologia, Universidade Estadual do Maranhão (UEMA) - São Luís (MA), Brasil.

*Autor correspondente: daniel@cernitas.com.br

Recebido em: 06/04/2015. Aceito em: 05/10/2016
} 


\section{INTRODUÇÃO}

A tuberculose é uma zoonose infectocontagiosa de caráter crônico, com distribuição mundial, caracterizada pela formação de tubérculos, que acomete quase todas as espécies de mamíferos (GATTI, 2010; REVOREDO, 2016). É provocada por bactérias pertencentes à ordem Actinomycetales, família Mycobacteriaceae, gênero Mycobacterium (CORRÊA; CORRÊA, 1992), que apresentam três espécies clássicas com diferentes graus de patogenicidade para as espécies animais: M. tuberculosis, M. bovis e M. avium (SILVA, 2013).

As principais vias de infecção são a respiratória, ocorrendo em 80 a $90 \%$ dos casos, e a digestiva, que ocorre principalmente em animais jovens quando alimentados com leite de fêmeas tuberculosas, sendo menos comuns as transmissões cutânea, transplacentária e genital (ABRAHÃO, 1999; FLEURY, 2010; BLANKENHEIM, 2016).

Não há registro de casos ou estudos sobre a tuberculose em ovinos no estado do Maranhão, em parte devido à criação ser considerada complementar à renda das propriedades. Esse fator, associado às poucas pesquisas sobre a enfermidade no estado, gera preocupação, uma vez que PEREIRA et al. (2009a; 2009b) encontraram prevalências para tuberculose de 12,12\% em bovinos leiteiros e 13,54\% em bubalinos, nos municípios de Santa Rita e Arari, respectivamente. Já RIBEIRO et al. (2011a) identificaram 28 (13,3\%) búfalos positivos em 4 propriedades no município de Viana, localizado na baixada maranhense.

Outro aspecto relacionado ao manejo da criação de ovinos é o indispensável contato mais direto e íntimo com o homem, fazendo com que esses animais possam atuar como veículo de transmissão e contágio de zoonoses.

A introdução da tuberculose no rebanho ovino ou sua propagaçáo é facilitada por práticas comuns de manejo, como alimentaçáo de pequenos ruminantes com leite de vacas contaminadas, ou sua manutenção em piquetes com rotação de pastagens com bovinos infectados (PINHEIRO, 2007).

Para o diagnóstico da tuberculose em bovinos, caprinos e ovinos, a prova tuberculínica é amplamente utilizada com a finalidade de obtençáo de resultados mensuráveis; e pode ser auxiliada com a realização de análises necroscópicas, bacteriológicas e histopatológicas a partir de tecidos lesados, obtidos por meio de biópsia ou retirados no momento da necropsia em animais positivos ao teste (CYRILLO et al., 2007; YURI, 2010; CARVALHO et al., 2011).

Em condiçóes brasileiras foi possível padronizar os valores para leitura da reaçáo à aplicaçáo intradérmica do derivado proteico purificado (PPD) em testes experimentais com caprinos (SILVA et al., 2006) e ovinos (CYRILLO et al., 2007). Esses exames foram repetidos, obtendo-se resultados semelhantes (CORRÊA, 2008; YURI, 2010; CARVALHO et al., 2011; SILVA, 2013), corroborando a utilizaçáo dos testes como técnica de rotina no diagnóstico da enfermidade nessas espécies (MARCONDES, 2007; ALMEIDA, 2009; PIGNATA et al., 2009).

O objetivo deste trabalho foi identificar casos de tuberculose no rebanho ovino maranhense, provenientes de áreas onde ocorre a maior concentração de criaçôes conjuntas com bovinos leiteiros, mais propensos a se infectarem com tuberculose, utilizando-se o teste cervical comparativo (TCC).

\section{MATERIAL E MÉTODOS}

Foram avaliados 343 ovinos, sendo 192 oriundos de 4 propriedades do município de Açailândia (0456'49”S/47030'18”W) e 151 de 6 propriedades de São Francisco do Brejão $\left(05^{\circ} 07^{\prime} 22^{\prime \prime} \mathrm{S} / 47^{\circ} 23^{\prime} 09^{\prime \prime} \mathrm{W}\right)$. As propriedades selecionadas se localizavam nos municípios que apresentavam os maiores efetivos bovinos leiteiros e produçấo de leite/dia, tendo como atividade principal a bovinocultura leiteira; e possuíam, no mínimo. 40 ovinos criados em manejo integrado com a outra espécie.

Os animais do estudo tinham idade superior a 6 meses, de ambos os sexos, sendo excluídas as fêmeas que se encontravam no período compreendido entre os 15 dias anteriores e os 15 dias após o parto, além das fêmeas em fase de amamentação e seus cordeiros em aleitamento, conforme orientaçấo contida no Manual do Programa Nacional de Controle e Erradicação da Brucelose e Tuberculose (PNCEBT) (BRASIL, 2006).

Os ovinos foram identificados e examinados clinicamente, avaliando-se os padrôes de coloração da mucosa, presença de linfonodos aumentados à palpação, frequência cardíaca, frequência respiratória, movimentos ruminais e temperatura retal.

Após a tricotomia, mediu-se a espessura da pele e inoculou-se, por via intradérmica, cranialmente, na regiáo cervical, $0,1 \mathrm{~mL}$ de PPD aviário (tuberculina aviária, Tecpar, $\left.0,5 \mathrm{mg} \cdot \mathrm{mL}^{-1}, 25.000 \mathrm{UI}\right)$ e, caudalmente, $0,1 \mathrm{~mL}$ de PPD bovino (tuberculina bovina, Tecpar, 1,0 mg. $\mathrm{mL}^{-1}$, 32.500 UI). A distância entre os locais de aplicação foi de $7 \mathrm{~cm}$, aproximadamente.

Decorridas $72 \pm 6$ horas da aplicação, realizou-se nova medida de espessura da pele, registrando-se os resultados em planilha apropriada para posterior comparaçáo e caracterização da reaçáo local às tuberculinas - interpretaçáo do teste pelo método TCC, obedecendo ao padrão estabelecido por CYRILLO et al. (2007), que consideraram: positiva a reação ao PPD bovino superior ao PPD aviário em pelo menos $2 \mathrm{~mm}$; inconclusiva, se a reação ao PPD bovino for maior do que aquela ao aviário, com diferença entre 1,0 e $1,9 \mathrm{~mm}$; e negativa quando o aumento da espessura da pele for menor do que a reação ao aviário ou maior até $0,9 \mathrm{~mm}$.

O trabalho foi aprovado pela Comissão de Ética e Experimentação Animal (CEEA) do Curso de Medicina Veterinária da Universidade Estadual do Maranhão (UEMA), sob o número 016/2013. 


\section{RESULTADOS}

Todos os ovinos foram negativos ao teste tuberculínico empregado. Ao exame clínico observou-se que as funçôes vitais (frequência respiratória e cardíaca, movimentos ruminais e temperatura) se apresentaram dentro dos limites fisiológicos para a espécie ovina (PUGH, 2005; AIELLO, 2001). Foram observados linfonodos superficiais aumentados, sugestivos de linfadenite caseosa, em seis ovinos.

Do total de 343 ovinos amostrados, 247 (72,01\%) eram fêmeas, sendo 244 (98,79\%) mestiças de Santa Inês e $3(1,21 \%)$ puras de origem (PO) da raça Santa Inês. Dos 96 (27,99\%) machos, 56 (58,33\%) não estavam castrados. Dos reprodutores atuando em rebanho mestiço de Santa Inês, 2 (3,57\%) ovinos eram PO da raça Dorper e $20(37,04 \%)$ eram mestiços de Santa Inês. Outros 34 (62,96\%) ovinos mestiços ainda não possuíam definição da finalidade de criação. Alguns desses seriam castrados ao atingirem a puberdade.

Apesar de não representar aumento significativo para se considerar a reação positiva, foi observado, no local de aplicaçáo da tuberculina bovina, aumento cutâneo em 5 $(1,46 \%)$ animais (1 macho e 4 fêmeas). Nestes, notou-se aumento leve da consistência (enrijecimento superficial da pele) no local de aplicaçáo de ambas as tuberculinas em quatro animais (um macho e três fêmeas); e uma fêmea apresentou maciez no local de aplicação da tuberculina bovina associada a um endurecimento no local de aplicação da tuberculina aviária.

No local de aplicação da tuberculina aviária foram observadas diversas reaçôes cutâneas, envolvendo diferentes quantitativos de animais. Esse fato sugere a interferência de micobactérias ambientais sobre o teste tuberculínico. No local da aplicação, 9 machos e 29 fêmeas apresentaram um leve enrijecimento da pele, sem o indicativo de dor ou sensibilidade; 1 macho e 8 fêmeas apresentaram enrijecimento superficial da pele sem presença de edema ou dor local; 1 fêmea exibiu um pequeno enrijecimento superficial da pele e sensibilidade local; e 3 fêmeas exibiram enrijecimento superficial e leve maciez no local de aplicação. $\mathrm{O}$ único animal do estudo a apresentar duas reaçóes simultâneas no mesmo local de inoculação foi um macho com enrijecimento consistente associado a um endurecimento superficial da pele.

No somatório das reaçóes locais, foi possível quantificar a maciez em 33 (9 machos e 24 fêmeas) ocorrências observadas.

A necropsia foi realizada em um ovino caquético, macho, com idade acima de quatro anos, que ao TCC apresentou negatividade para tuberculose, apresentando 2,7 de diferença entre $\Delta \mathrm{B}$ e $\Delta \mathrm{A}$. Porém, apresentou reaçáo de consistência local, com leve endurecimento superficial da pele no local de aplicação da tuberculina aviária.

No exame clínico, foi observada a presença de linfonodos aumentados (pré escapulares, bilaterais - cervical superficial, submandibular), de consistência endurecida, sugestivos de linfadenite caseosa. Foram coletados fragmentos do pulmão, linfonodos pulmonares, fígado e linfonodos cervicais para a realização de exames histopatológicos (com coloração especial de Ziehl Neelsen), além de amostras de secreção nasal e secreção das lesões em linfonodos, para isolamento do agente.

Foi observado o parênquima pulmonar exibindo pneumonia bronco-intersticial mista moderada multifocal subaguda. No fragmento de linfonodo pulmonar, constatou-se hiperplasia linfoide reativa. O exame microscópico do fragmento de fígado revelou hepatite mista multifocal moderada subaguda. No linfonodo submandibular verificou-se linfadenite piogranulomatosa focal severa. A amostra de linfonodo pré-escapular revelou hiperplasia linfoide reativa associada à área de necrose.

Para identificação de possíveis micobacterioses, foi realizado exame histopatológico com coloração especial de Ziehl-Neelsen, não sendo visualizadas estruturas bacterianas compatíveis com bacilos álcool ácido resistentes (BAAR).

A cultura de bactérias a partir da amostra de secreção nasal revelou um crescimento abundante de Pseudomonas aeruginosa; no exsudato do linfonodo, isolou-se Bacillus sp.

\section{DISCUSSÃO}

De acordo com os padróes estabelecidos por CYRILLO et al. (2007) para a interpretaçáo do teste imunológico de tuberculina aplicado ao diagnóstico de tuberculose em ovinos, o total de animais testados foi considerado negativo ao TCC. Desses, 65 animais apresentaram reaçáo à tuberculina bovina superior à aviária $(\Delta \mathrm{B}-\Delta \mathrm{A} \geq 0)$, porém, sem aumento que significasse positividade ao teste, enquanto 278 ovinos apresentaram reação à tuberculina bovina inferior à aviária $(\Delta \mathrm{B}-\Delta \mathrm{A} \geq 0)$. Isto pode ser explicado pelo fato da reação alérgica à tuberculina indicar que há possibilidade do organismo estar infectado por bacilos virulentos, atenuados, inativados, vacinais ou ambientais; não significando imunidade contra a tuberculose, concordando com as afirmações de BRASIL (2006).

Para HIGINO et al. (2013), o grande número de reaçóes inespecíficas pode estar relacionado à forma de pastejo dos ovinos, realizada rente ao solo, o que aumenta a probabilidade de ingestão de micobactérias ambientais que têm como habitat solo, água, poeira e aerossóis. PIGNATA et al. (2009) argumentaram que, em caprinos, essas reaçóes são decorrentes do contato dos animais com aves (galinhas), principalmente em propriedades onde a criação das aves é próxima a currais ou há contato direto com ruminantes, prática semelhante à adotada nas propriedades da área estudada.

ALZAMORA FILHO (2013) acrescentou que outras espécies de micobactérias não causadoras de tuberculose presentes 
no ambiente podem desencadear doenças com quadro de enfermidade pulmonar e extrapulmonar, principalmente em indivíduos imunossuprimidos.

Considerando que o rebanho bovino leiteiro apresenta uma maior incidência de tuberculose quando comparado com o gado de corte (ROXO, 1997); que os ovinos amostrados são criados em consorciaçáo com aqueles bovinos e a ausência de notificaçóes de tuberculose bovina na área pesquisada, os resultados deste estudo podem indicar que é pouco provável a presença da enfermidade no local.

A tuberculose foi, por muito tempo, considerada rara nos ovinos, ou subestimada nessa espécie pelos pequenos números de ocorrência frente à grande prevalência da enfermidade nos bovinos (CYRILLO et al., 2007). Porém, várias pesquisas no Brasil e no mundo comprovam que a espécie pode contrair a enfermidade a partir de outros animais (KASSA et al., 2012; MALONE et al., 2003; MARIANELLI et al., 2010, MENDONZA et al., 2012; TSCHOPP et al., 2011; VAN DER BURGT et al., 2013).

ALLEN (1988) destacou que, embora o pequeno número de casos de tuberculose ovina possa ser confundido com outras doenças mais comuns das ovelhas, é provável que uma combinação de fatores comportamentais e de criação possa tornar a doença em ovelhas extremamente rara, independentemente do verdadeiro nível de suscetibilidade.

Os hábitos das propriedades amostrais refletem os métodos adotados na região sudoeste maranhense para criação de ovinos. Foram observadas práticas que podem contribuir para a disseminação da tuberculose entre diferentes espécies, como utilização da mesma pastagem para aumento de sua eficiência, ou como meio de controle de parasitos gastrintestinais; suplementação alimentar de borregos com leite de vacas não testadas para tuberculose; criação extensiva de ovinos sem nenhum controle reprodutivo, mínimo controle sanitário, restrito apenas à aplicaçáo de vermífugos; escassa assistência veterinária, fazendo com que enfermidades sejam desconhecidas ou subestimadas; práticas de tratadores em romper abscessos em linfonodos aumentados, sem a orientaçáo de médico veterinário, sem utilização de materiais mínimos que possam protegê-los de uma infecção por diferentes zoonoses ou cuidados que não permitam a contaminaçáo do ambiente.

Portanto, a baixa frequência de tuberculose na regiáo deve servir como um alerta para a tomada de decisóes e náo como justificativa de uma aparente situaçáo de controle, uma vez que focos em pequenos ruminantes foram identificados a partir de animais de diferentes estados brasileiros como Minas Gerais, Paraná, Pernambuco, Paraíba e São Paulo, com um total de 27 (72,00\%) caprinos (ALMEIDA, 2009); São Paulo registrando 1 caprino positivo (BENESI et al., 2008); Paraíba, com o registro de $1(8,33 \%)$ caprino e $2(7,14 \%)$ ovinos positivos (HIGINO et al., 2013); Pernambuco com 15 (3,40\%) caprinos positivos (MELO et al., 2012); Paraíba, com 9 (0,48\%) caprinos positivos (PIGNATA et al., 2010) e Pernambuco, com $11 \pm 11,80 \%$ dos caprinos positivos (SILVA et al., 2009).

Casos de reaçáo cutânea concomitante às aplicaçóes de tuberculinas aviária e bovina foram também encontrados por FERNÁNDEZ BENITO et al. (2001), que demonstraram a presença de tuberculose e paratuberculose em rebanhos caprinos por meio de testes baseados em intradermorreações.

GUTIÉRREZ; GARCÍA MARÍN (1999) indicaram que há possibilidade de vários agentes atuarem no mesmo animal, manifestando sinais clínicos não patognomônicos, dificultando o diagnóstico de doenças. Esses autores encontraram presença concomitante de Cryptococcus neoformans e $M$. bovis em uma cabra. Eles concluíram que houve sinergia entre os dois agentes patogênicos, sendo os fungos responsáveis pela falta de resposta imune celular humoral nos testes de tuberculose.

Já MARCONDES (2007), após aplicação de teste tuberculínico em ovinos, isolou micobactérias de sete animais. Exames bacteriológicos para outras bactérias e/ou fungos isolaram C. pseudotuberculosis, havendo, em dois animais, isolamento simultâneo de micobactérias e $C$. pseudotuberculosis, resultado também encontrado em amostra desta pesquisa.

ABREU et al. (2008) demonstraram uma pluralidade de agentes infecciosos envolvidos nos processos abscedativos dos pequenos ruminantes ao encontrarem crescimento de mais de um tipo de micro-organismo em cultura do conteúdo dos abscessos superficiais sugestivos de linfadenite. Os autores isolaram bactérias em associação a C. pseudotuberculosis, com destaque a Staphylococcus sp. e bactérias Gram-negativas não identificadas, corroborando achados semelhantes encontrados por SAIID et al. (2002), que relataram o isolamento de Staphyloccocus aureus subsp. anaerobius, Streptoccocus sp., entre outros. Esses agentes também foram encontrados nesta pesquisa.

Os achados histopatológicos indicaram infecçôes bacterianas, fúngicas e parasitárias. Em ovinos, os agentes mais comuns que causam essas lesóes são o Corynebacterium pseudotuberculosis, Actinomyces pyogenes, Staphylococcus aureus e Mycobacterium sp.

VALENÇOELA et al. (2012) caracterizaram as bactérias presentes em abscessos de ovinos abatidos no estado de Mato Grosso do Sul, identificando C. pseudotuberculosis, enterobactérias, Staphylococcus sp. e Arcanobacterium pyogenes. Já HIGINO et al. (2013), em pesquisa a partir de linfonodos hipertrofiados ou com lesóes macroscópicas sugestivas de tuberculose, colhidos de caprinos e ovinos abatidos em Patos, na Paraíba, isolaram micobactérias (complexo M. tuberculosis), micobactérias ambientais e $C$. pseudotuberculosis. Realizaram ainda o isolamento simultâneo de micobactérias e $C$. pseudotuberculosis em um ovino e um caprino.

O C. pseudotuberculosis é o causador da linfadenite caseosa, doença infectocontagiosa de pequenos ruminantes domésticos 
(ABREU et al., 2008). A linfadenite apresenta lesóes macroscópicas semelhantes às da tuberculose (HIGINO et al., 2013). Para RIBEIRO et al. (2011b), outros micro-organismos também estão envolvidos na gênese da linfadenite infecciosa em ovinos, entre eles a Pseudomonas aeruginosa. Esse agente também foi encontrado nos resultados laboratoriais da secreção nasal da amostra deste estudo.

A ausência de ovinos positivos para tuberculose na área estudada, indicando uma baixa incidência do agente no ambiente, não descarta a necessidade de medidas de controle e erradicação (MELO et al., 2012), como, entre outras, a verificação da enfermidade em outras espécies animais criadas na regiáo, não somente naquelas contempladas pelo PNCEBT, uma vez que foi observada no local a criação conjunta de bovinos, suínos, ovinos, caprinos, equídeos, cáes e gatos, compartilhando as mesmas instalaçôes.

Isto deve ser considerado no estudo epidemiológico de enfermidades e medidas de controle para o Maranhão, uma vez que os manejos com animais adotados na área de estudo náo diferem da realidade apresentada por diversas criaçóes de animais distribuídas no estado, concordando com açôes sugeridas por SILVA et al. (2011), que acrescentaram a necessidade de implantação de políticas públicas com açôes voltadas para a educação sanitária dos criadores, busca de conscientização dos riscos causados pela tuberculose, monitoramento e controle do trânsito de reprodutores, revisão e aplicação de normas sanitárias.

\section{CONCLUSÕES}

Conclui-se que a ausência de animais reagentes ao $M$. bovis pressupôe a inexistência da tuberculose em ovinos na região estudada.

A maior reação à tuberculina aviária, quando comparada à reação à tuberculina bovina, é um indicativo de reação inespecífica, ou ainda, uma possível contaminação dos animais por micobactérias presentes no meio ambiente.

A comprovação laboratorial da interferência do $C$. pseudotuberculosis e de outros agentes na prova da tuberculina em ovinos corrobora a indicaçáo do emprego da técnica do TCC associada a métodos de diagnóstico que permitam o isolamento de agentes, principalmente naquelas enfermidades em que os sinais clínicos e de comprometimento linfático sejam confundíveis com os da tuberculose.

\section{AGRADECIMENTOS}

À Fundação de Amparo à Pesquisa e Desenvolvimento Científico do Maranháo (FAPEMA) pelo apoio financeiro; ao Fundo de Desenvolvimento da Pecuária do Estado do Maranháo (FUNDEPEC/MA), à Agência Estadual de Defesa Agropecuária do Maranháo (AGED/MA) e à Universidade Estadual do Maranhão (UEMA), por tornarem possível esta pesquisa.

\section{REFERÊNCIAS}

ABRAHÃO, R.M.C.M. Tuberculose humana causada pelo Mycobacterium bovis: considerações gerais e a importância dos reservatórios animais. Archives of Veterinary Science, Curitiba, v.4, n. 1, p.5-5, 1999.

ABREU, S.R.O.; MOTA, R.A.; ROSINHA, G.M.S.; FOMER, O.; PINHEIRO JÚNIOR, J.W.; PEREIRA, R.R.B.; CASTRO, R.S.; ELISEI, C.; SOARES, C.O.; ARAÚJO, F.R.; MADUREIRA, R.C. Comparação genotípica de isolados de Corynebacterium pseudotuberculosis de caprinos e ovinos do sertão de Pernambuco. Pesquisa Veterinária Brasileira, Seropédica, v.28, n.10, p.481-487, 2008.

AIELLO, S. (Ed.). Manual merck de veterinária. São Paulo: Roca, 2001.

ALLEN, G.M. Tuberculosis in sheep: a very rare disease. Surveillance, Nova Zelândia, v.15, n.5, p.8-9, 1988.

ALMEIDA, C.A.S. Avaliação do teste cervical comparativo no diagnóstico imunoalérgico da tuberculose em caprinos (Capra hircus). 2009. 88f. Dissertação (Mestrado em Medicina Veterinária)Faculdade de Medicina Veterinária e Zootecnia, Universidade de São Paulo, São Paulo, 2009.
ALZAMORA FILHO, F. Diagnóstico bacteriológico e molecular da tuberculose bovina a partir de lesões de bovinos abatidos no estado da Bahia. 2013. 99f. Tese (Doutorado em Ciência Animal nos Trópicos) - Escola de Medicina Veterinária e Zootecnia, Universidade Federal da Bahia, Salvador, 2013.

BENESI, F.J.; PINHEIRO, S.R.; MAIORKA, P.C.; SAKAMOTO, S.M.; ROXO, E.; BENITES, N.R.; BIRGEL JUNIOR, E.H.; GREGORY, L. Tuberculose em caprino (Capra hircus): relato de caso. Arquivos do Instituto Biológico, São Paulo, v.75, n.2, p.217-220, 2008.

BLANKENHEIM, T.M. Resposta à tuberculinização em bovinos sensibilizados com inóculos inativados de Mycobacterium avium $e$ Mycobacterium bovis. 2016. 120f. Tese (Doutorado em Medicina Veterinária)-Faculdade de Ciências Agrárias e Veterinária, Universidade Estadual Paulista, Jaboticabal, 2016.

BRASIL. Ministério da Agricultura, Pecuária e Abastecimento. Programa Nacional de Controle e Erradicação da Brucelose e da Tuberculose Animal (PNCEBT). Brasília: MAPA/SDA/DAS, 2006. 188p. 
CARVALHO, R.B.; SILVA JUNIOR, L.S.; LIMA, D.S.; SAMPAIO, M.P.; PEDROSO, P.O.; CERQUEIRA, R.B. Padronização de um teste alérgico para tuberculose em ovinos localizado na universidade federal do recôncavo da Bahia (UFRB). Revista de Ciências Agroveterinárias, Lages, número especial, 2011 . Disponível em: <http://www.sovergs.com.br/site/38conbravet/listaresumos. htm>. Acesso em: 22 maio 2012.

CORRÊA, J.G.Z. Estudo da resposta alérgica à tuberculina em caprinos (Capra hircus) experimentalmente sensibilizados, em diferentes regiões corpóreas. 2008. $81 \mathrm{f}$. Dissertação (Mestrado em Medicina Veterinária)-Faculdade de Medicina Veterinária e Zootecnia, Universidade de São Paulo, São Paulo, 2008.

CORRÊA, W.M.; CORRÊA, C.N.M. Enfermidades infecciosas dos mamíferos domésticos. Rio de Janeiro: Medsi, 1992.

CYRILLO, F.C.; LEAL, M.L.R.; MOTTA, P.M.P.C.; SINHORINI, I.L.; VASCONCELLOS, S.A.; PINHEIRO, S.R.; BENESI, F.J. Teste de tuberculinização em ovinos (Ovis aries) experimentalmente sensibilizados. Arquivos do Instituto Biológico, São Paulo, v.74, n.3, p.191-197, 2007.

FERNÁNDEZ BENITO, V.; SÁNCHEZ GARCIA, R.; VELASCO DIEGO, J. Estimulación serológica e intradermorreacción doble (tuberculosis-paratuberculosis) em 30 rebaños caprinos de la Comarca de Béjar (Salamanca). In: JORNADAS CIENTÍFICAS Y INTERNACIONALESDELA SOCIEDAD ESPAÑOLA DEOVINOTECNIA Y CAPRINOTECNIA, 26., Sevilla, 2001. Anais... Sevilla, 2001. p.697-704.

FLEURY, C.M.F. Determinação de imunogenicidade de proteínas de Mycobacterium bovis isolados de bovinos naturalmente infectados no estado de Goiás. 2010. 50f. Dissertação (Mestrado em Ciência Animal)-Escola de Veterinária e Zootecnia, Universidade Federal de Goiás, Goiânia, 2010.

GATTI, G.L. Tuberculose e sua importância para a pecuária brasileira. 2010. 20f. Monografia (Grau de Médico Veterinário)-Faculdade de Medicina Veterinária e Zootecnia da Universidade Paulista “Júlio de Mesquita Filho", Botucatu, 2010.

GUTIÉRREZ, M.; GARCÍA MARÍN, J.F. Cryptococcus neoformans and Mycobacterium bovis causing granulomatous pneumonia in a goat. Veterinary Pathology Online, v.36, n.5, p.445-448, 1999. Disponível em: <http://vet.sagepub.com/content/36/5/445>. Acesso em: 14 jul. 2014.

HIGINO, S.S.S.; PINHEIRO, S.R.; ROCHA, V.C.M.; SOUZA, G.O.S.; PORTELA, R.A.; ALVES, C.J.; VASCONCELLOS, S.A.; DIB, C.C.; ROSÁRIO, T.R.; MELVILLE, P.A.; AZEVEDO, S.S. Tuberculose em caprinos e ovinos abatidos no semiárido da Paraíba, Brasil. Arquivos do Instituto Biológico, São Paulo, v.80, n.3, p.281-287, 2013.

KASSA, G.M.; ABEBE, F.; WORKU, Y.; LEGESSE, M.; MEDHIN, G.; BJUNE, G.; AMENI, G. Tuberculosis in goats and sheep in Afar Pastoral Region of Ethiopia and isolation of Mycobacterium tuberculosis form goat. Veterinary Medicine International, v. 2012, 2012. 8p. DOI: 10.1155/2012/869146. Disponível em: <http://www.hindawi.com/journals/vmi/2012/869146/>. Acesso em: 3 out. 2012.
MALONE, F.E.; WILSON, E.C.; POLLOCK, J.M.; SKUCE, R.A. Investigations into an outbreak of tuberculosis in a flock of sheep in contact with tuberculous cattle. Journal of Veterinary Medicine, Oxford, v.50, n. 10, p.500-504, 2003. Series B.

MARCONDES, A.G. Micobacteriose de ovinos (Ovis aries) do Estado de São Paulo, Brasil: correlação entre teste imunoalérgico, cultivo e histopatológico. 2007. 93f. Tese (Doutorado em Medicina Veterinária) - Faculdade de Medicina Veterinária e Zootecnia, Universidade de São Paulo, São Paulo, 2007.

MARIANELLI, C.; CIFANI, N.; CAPUCCHIO, M.T.; FIASCONARO, M.; RUSSO, M.; MANCUSA, F.; PASQUALI, P.; DI MARCO, V. A case of generalized bovine tuberculosis in a sheep. Journal of Veterinary Diagnostic Investigation, Ontário, v.22, n.3, p.445-448, 2010. Disponível em: <http://vdi.sagepub.com/content/22/3/445>. Acesso em: 3 out. 2012.

MELO, E.H.; MOTA, R.A.; MAIA, F.C.L.; FERNANDES, A.C.C.; SILVA, T.I.B.; LEITE, J.E.B.; BAPTISTA FILHO, L.C.F; RAMOS, C.A.N. Ocorrência e caracterização da tuberculose em caprinos leiteiros criados no estado de Pernambuco. Pesquisa Veterinária Brasileira, Soropédica, v.32, n.9, p.831-837, 2012.

MENDONZA, M.M.; JUAN, L.; MENÉNDEZ, S.; OCAMPO, A.; MOURELO, J.; SÁEZ, J.L.; DOMÍNGUEZ, L.; GORTÁZAR, C.; GARCÍA MARÍN, J.F.; BALSEIRO, A. Tuberculosis due to Mycobacterium bovis and Mycobacterium caprae in sheep. The Veterinary Journal, Londres, v.191, n.2, p.267-269, 2012.

PEREIRA, H.M.; SANTOS, H.P.; BEZERRA, D.C.; ARAGÃO, A.C.C.; SOUSA, V.E. Ocorrência de tuberculose em rebanho bubalino (Bubalus bubalis var. Bubalis - Linneus, 1758) em uma propriedade do município de Arari, Maranhão, Brasil. Ciência Animal Brasileira, Goiânia, v.10, p. 546-550, 2009a.

PEREIRA, H.M.; SANTOS, H.P.; BEZERRA, D.C.; PEREIRA, D.P. Ocorrência da tuberculose em rebanho bovino de uma propriedade do município de Santa Rita, Maranhão, Brasil. Ciência Animal Brasileira, Goiânia, v.10, p. 508-512, 2009b.

PIGNATA, W.A.; ALVES, C.J.; AZEVEDO, S.S.; DANTAS, A.F.M.; GOMES, A.A.B.; REMÍGIO, F.R.; LIMA, F.S.; MOTA, P.M. Prevalência para tuberculose em caprinos no semiárido paraibano. Pesquisa Veterinária Brasileira, Soropédica, v.29, n.7, p.526-532, 2009.

PIGNATA, W.A.; ALVES, C.J.; AZEVEDO, S.S.; PINHEIRO, S.R.; VASCONCELLOS, S.A.; ALMEIDA, C.A.S.; DANTAS, A.F.M.; REMÍGIO, F.R. Tuberculose em caprinos no semiárido brasileiro. Arquivos do Instituto Biológico, São Paulo, v.77, n.2, p.339-342, 2010.

PINHEIRO, S.R. A tuberculose é uma triste realidade. O Berro, Uberaba, n. 104, p.52-55, 2007.

PUGH, D.G. Clínica de ovinos e caprinos. São Paulo: Roca, 2005. $513 p$.

REVOREDO, R.G. Identificação do M. bovis em amostras sorológicas pela PCR em rebanhos de bovinos leiteiros de Pernambuco. 2016. 56f. Dissertação (Mestrado em Ciência Veterinária)-Universidade Federal Rural de Pernambuco, Recife, 2016. 
RIBEIRO, D.L.S.; SANTOS, L.S.; CARDOSO, D.L.; SOUZA, O.A.F.; SOUSA, K.L.M.; MADEIRA, R.L.; SANTOS, H.P.; MELO, F.A. Serological diagnosis of Mycobacterium bovis in buffaloes (Bubalus bubalis) in the region of Viana, Maranhão, Brazil. Veterinaria e Zootecnia, Botucatu, v. 18, n.4, p.839-841, 2011 a. Disponível em: <http://www.fmvz.unesp.br/rvz/index.php/rvz/article/ viewFile/440/334>

RIBEIRO, M.G.; BELOTTA, A.F.; FERNANDES, M.C.; GUENA, R.; NARDI JUNIOR, G; LARA, G.H.B.; GIUFFRIDA, R.; ZAMPROGNA, T.O. Citologia aspirativa no diagnóstico de linfadenite em ovinos. Pesquisa Veterinária Brasileira, Soropédica, v.31, n.10, p.839-843, $2011 \mathrm{~b}$

ROXO, E. M. bovis como causa de zoonose. Revista Brasileira de Ciências Farmacêuticas, São Paulo, v. 18, n. 1, p.101-108, 1997.

SAÏD, M.S.B.; MAITIGUE, H.B.; BENZARTI, M.; MESSADI, L.; REJEB, A.; AMARA, A. Contribution a l'etude epidemiologique et clinique de la lymphadenite caseeuse chez les ovins. Revue des Archives de l'Institut Pasteur de Tunis, Tunísia, v.79, n. 1-4, p.51-57, 2002.

SILVA, F.D.S.; SANTOS, N.A.F; PACHECO, E.O.; LOPES, I.S.; PINHEIRO, M.F.N.; MAIA, M.P. Prevalência da brucelose bovina no estado do Maranhão, Brasil. Revista de Ciências Agroveterinárias, Lages, v. 10, p. 1-3, 2011 . Disponível em: <http://www.sovergs.com.br/ site/38conbravet/resumos/754.pdf>. Acesso em: 22 maio 2012.

SILVA, L.T. Estudo da tuberculose por Mycobacterium bovis em caprinos leiteiros no semi-árido baiano. 2013. 93f. Dissertação (Mestrado em Defesa Agropecuária)-Universidade Federal do Recôncavo da Bahia, Cruz das Almas, 2013.

SILVA, P.E.G.; PINHEIRO, S.R.; LEAL, M.L.R.; BERTAGNON, H.G.; MOTTA, P.M.P.C.; SINHORINI, I.L.; VASCONCELLOS, S.A.; BENESI, F.J. Teste de tuberculinização em caprinos (Capra hircus) experimentalmente sensibilizados. Ciência Rural, Santa Maria, v.36, n.3, p.880-886, 2006.

SILVA, T.I.B.; FERNANDES, A.C.C.; MENEZES, T.M.; VASCO NETO, H.L.S.; SILVA, D.D.; CUNHA, W.R.X.; MELO, L.E.H.; MENDES, E.I. Monitoramento clínico-epidemiológico, hematológico e etiológico relacionado ao diagnóstico diferencial entre tuberculose caprina e linfadenite caseosa. In: JORNADA DE ENSINO, PESQUISA E EXTENSÃO (JEPEX), 9., Recife, 2009. Anais eletrônicos... Recife: UFRPE, 2009. Disponível em: <http://www.eventosufrpe.com.br/ jepex2009/cd/resumos/r0665-2.pdf>. Acesso em: 8 set. 2012.

TSCHOPP, R.; BOBOSHA, K.; ASEFFA, A.; SCHELLING, E.; HABTAMU, M.; IWNETU, R; HAILU, E.; FIRDESSA, R.; HUSSEIN, J.; YOUNG, D.; ZINSSTAG, J. Bovine tuberculosis at a cattle-small ruminant-human interface in Meskan, Gurage region, Central Ethiopia. BMC Infectious Diseases, Londres, v.11, n.318, p.1-10, 2011. Disponível em: <http://www.biomedcentral.com/1471-2334/11/318>. Acesso em: 3 out. 2012.

VALENÇOELA, R.A.; RODRIGUES, F.S.; RODRIGUES, O.A.; GUIMARÃES, E.B.; LEAL, C.R.B. Estudo bacteriológico e histológico de abscessos em ovinos abatidos em Campo Grande, Mato Grosso do Sul. Veterinária em Foco, Canoas, v.9, n.2, p.158-163, 2012.

VAN DER BURGT, G.M.; DRUMMOND, F.; CRAWSHAW, T.; MORRIS, S. An outbreak of tuberculosis in Lleyn sheep in the UK associated with clinical sings. Veterinary Record, Londres, v.172, n.3, p.69, 2013.

YURI, D.M.R.S. Estudo da resposta alérgica à tuberculina em ovinos (Ovis aries) experimentalmente sensibilizados, conforme a região corpórea e a dose de ppd utilizada. 2010. 80f. Dissertação (Mestrado em Ciências)-Faculdade de Medicina Veterinária e Zootecnia, Universidade de São Paulo, São Paulo, 2010. 